\title{
ASPECTOS PRODUTIVOS E ECONÔMICOS DA CADEIA PRODUTIVA DO CIPÓ-PRETO NO LITORAL PARANAENSE
}

\author{
Alex Sandro Nogueira*, Anadalvo Juazeiro dos Santos**, Alexandre Muzy Bittencourt*, \\ Dalvo Ramires Bolzon***, Fernanda da Silva de Paula**** \\ *Eng. Florestal, Mestrando em Eng. Florestal, UFPR - alexsandro@ufpr.br \\ **Eng. Florestal, Dr., Depto. de Economia Rural e Extensão, UFPR - ajsantos@floresta.ufpr.br \\ ***Economista, Doutorando em Eng. Florestal, UFPR \\ ****Acadêmica de Biologia, PUC/PR
}

Recebido para publicação: 06/09/2005 - Aceito para publicação: 15/08/2006

\begin{abstract}
Resumo
O recurso vegetal Philodendron melanorrhizum Reitz, conhecido popularmente como cipó-preto, é uma importante fonte de renda para as comunidades que vivem inseridas em unidades de conservação, como é o caso das populações da APA de Guaratuba. A presente pesquisa teve como objetivo descrever, do ponto de vista econômico, a cadeia produtiva do cipó-preto no litoral paranaense, que contempla as atividades desde a extração na floresta até a utilização final na forma de artesanato. Para atingir tais objetivos, a metodologia utilizada constituiu-se das seguintes etapas: localização da cadeia produtiva, análise da estrutura de mercado, dos contextos organizacional e institucional, dos fluxos físicos e financeiros e das limitações e potencialidades da cadeia. Os dados técnicos e econômicos foram obtidos através de entrevistas com os produtores, comerciantes, instituições públicas e privadas do estado do Paraná. Evidenciou-se a ocorrência de 200 produtores trabalhando com artesanato de cipó-preto. No período de execução do trabalho, eram coletados anualmente, em média, $23.000 \mathrm{~kg}$ de cipó-preto, e produzidas 77.760 unidades de artesanato. $\mathrm{O}$ custo de produção médio do artesanato foi de $\mathrm{R} \$ 1,57$ por unidade. No comércio, a média de venda dos artesanatos foi de 60 unidades/mês, e o preço médio de venda era R $\$ 6,79$ por unidade. O "markup" de comercialização total da cadeia foi $869,24 \%$. Com a execução da presente pesquisa, concluiu-se que: 1) a estrutura da cadeia produtiva do cipó-preto é bastante simplificada; 2) a maior parte do lucro fica com os atacadistas; 3 ) o consumidor final paga $869,24 \%$ a mais sobre o preço inicial do produtor. Palavras-chave: Philodendron melanorrhizum Reitz; produto florestal não-madeireiro; unidades de conservação; extrativismo.
\end{abstract}

Abstract
Productive and economic aspects in productive chain of black vine in Parana seaside. The wild
vegetal resource Philodendron melanorrhizum Reitz, known as black vine, is an important outcome
resource for the communities living in the conservation units, as for the Guaratuba APA population.
This research had as objective to describe in an economic point of view, the black vine productive
chain in Parana seaside, focusing on the activities since the forest extraction up to its utilization as
handcraft raw material. To achieve these objectives, the methodology consisted of the following
steps: productive chain location, market structure analysis, organizational and institutional contexts,
physical and financial flows, chain limitations and potential. The technical data was obtained through
producers, purchasers, state and private institutions interviews in the state of the Paraná. The results
shown that, in the region, there are 200 producers working on black vine handmade products. They
are collected annually, an average of $23.000 \mathrm{~kg}$ of black vine and produced 77.760 handmade
products. The medium production cost was of $\$ \$ 1,57$ per unit. In the commerce, the average sales of
the handmade products is of 60 units/month and the sales average price is R $\$ 6,79$ per unit. The total
commercialization markup of the chain is of $869,24 \%$. According to the current resource, it was
concluded that: 1 ) The black vine productive chain structure is very simple; 2 ) The largest part of the
profit remains with the distributors; 3 ) The final consumer pays $869,24 \%$ more over the producer
initial price.
Keywords: Philodendron melanorrhizum Reitz; no-wood forest product; conservation units; Extraction. 


\section{INTRODUÇÃO}

Em toda a história humana, as florestas tropicais têm sido valorizadas pela variedade de produtos e benefícios que dela provêm, tanto para a subsistência como para o comércio, tais como alimentos, produtos medicinais, especiarias, resinas, gomas, látex, vida selvagem, combustível, madeira e outros produtos não-madeireiros (SANTOS et al., 2004).

Em quase toda a era moderna, o desenvolvimento da perspectiva da atividade florestal tem-se limitado aos recursos de apenas um produto: madeira. Essas perspectivas resultam em um uso intensivo dos recursos madeireiros, em detrimento da constante desconsideração do restante do ecossistema florestal (SANTOS et al., 2004).

Enquanto, em termos econômicos, a madeira é um recurso renovável, ela ao mesmo tempo é um componente indispensável da estrutura e funcionalidade da floresta. A madeira fornece o suporte físico para o dossel de folhas que fornece a energia e a sombra da floresta, conduz a água até as folhas a uma altura maior que um edifício de quinze andares e é responsável pela reposição de boa parte do carbono da floresta. É impossível explorar grandes quantidades de madeira de uma floresta sem alterar sua estrutura tridimensional, seu fluxo de água e energia ou seu estoque de carbono. Planos de manejo de florestas naturais que admitam que a floresta se recupere entre explorações sucessivas e cuidadosamente planejadas são teoricamente possíveis, mas na realidade inexistentes nas florestas tropicais do mundo.

A prática ancestral economicamente viável de extração dos produtos florestais não-madeireiros (PFNM), que mantém a estrutura e funcionalidade da floresta intacta, tem surgido como um meio capaz de harmonizar os papéis conflitantes das florestas tropicais (NEPSTAND, 1992). Vários estudiosos argumentam que o uso econômico dos PFNMs, através do desenvolvimento de seu mercado, possibilitam alcançar o desenvolvimento sustentável dos povos das florestas, na medida em que concilia eqüidade social, valores éticos e culturais, prudência ecológica e eficiência econômica (REYDON et al., 2002).

Segundo Sonda (2002), a utilização de Philodendron melanorrhizum Reitz (Araceae), conhecido popularmente por cipó-preto, como matéria-prima para a produção de artesanato tem sido uma importante fonte de renda para as comunidades que vivem na Área de Proteção Ambiental (APA) de Guaratuba (Paraná, Brasil).

A extração PFNM representa uma atividade econômica de baixo impacto ambiental e por isso pode ocorrer dentro de áreas de conservação, desde que subordinada à legislação específica. No caso das APAs, muitas vezes essa legislação impede o desenvolvimento de atividades econômicas mais intensivas, como, por exemplo, a agricultura, restando aos moradores locais práticas relacionadas à exploração extrativista de recursos florestais.

É nesse contexto que a análise das atividades extrativistas desenvolvidas nessas regiões torna-se extremamente necessária, numa perspectiva de geração de trabalho e renda aliada à conservação dos ecossistemas.

Dessa forma, o presente trabalho objetiva analisar alguns aspectos produtivos e econômicos da cadeia produtiva do cipó-preto, um PFNM que representa uma opção de renda para as populações locais.

Especificamente, pretende-se construir um fluxograma da cadeia produtiva do cipó-preto, definindo seus principais fluxos, bem como analisando suas margens e "markups" de comercialização.

\section{MATERIAL E MÉTODO}

O presente estudo foi desenvolvido entre os meses de janeiro e agosto de 2004, na Área de Proteção Ambiental de Guaratuba, que possui uma área de aproximadamente 200 mil hectares, englobando o município de Guaratuba e ainda parte dos de Matinhos, Tijucas do Sul, São José dos Pinhais e Morretes.

O recurso vegetal base da cadeia produtiva estudada foi Philodendron melanorrhizum Reitz, popularmente conhecido como cipó-preto, pertencente à família Araceae, a qual compreende cerca de 105 gêneros e aproximadamente 3300 espécies de herbáceas e trepadeiras (MAYO et al., 1997). Segundo Bogner e Nicolson (1991), as Araceaes são divididas em 9 subfamílias: Gymnostachydoideae, Pothoideae, Monsteroideae, Calloideae, Lasioideae, Philodendroideae, Colocasioideae, Aroideae e Pistioideae. A subfamília Philodendroideae inclui a tribo Philodendreae, à qual pertence o gênero Philodendron. A família possui ampla distribuição e é predominantemente tropical. Está representada no 
Brasil por 30 gêneros, entre os quais Philodendron, com aproximadamente 155 espécies (MAYO et al., 1994).

A espécie Philodendron melanorrhizum Reitz exibe hábitos de hemi-epífitas lianescentes, isto é, a espécie é conectada ao solo por raízes alimentadoras, embora a maior parte do seu caule desenvolva-se anexado aos troncos de árvores por raízes grampiformes, e freqüentemente se reproduz, vegetativamente, por ramos flageliformes. O caule jovem é monopodial e produz uma sucessão de folhas alternadas com bainhas bem desenvolvidas. Geralmente, a espécie ocupa lugares sombreados.

Para a execução deste trabalho, foram coletados dados primários referentes às quantidades extraídas, consumidas e comercializadas, ao custo de extração e de transporte, como também preços de mercado. Esses dados foram obtidos em pesquisa de campo junto a 86 produtores (extratores e artesãos), 11 varejistas e 2 atacadistas da região. Além de dados quantitativos, foram levantadas as características dessa cadeia produtiva junto às instituições públicas e privadas, ligadas às atividades agroflorestais no estado do Paraná.

A partir dos dados coletados, foi elaborado o fluxograma da cadeia produtiva e analisados aspectos referentes aos fluxos físicos e financeiros.

Para analisar os ganhos nos diferentes elos da cadeia de comercialização, foram usados os conceitos de Margem e Markup de Comercialização.

\section{RESULTADOS E DISCUSSÃO}

A atividade extrativista do cipó-preto inicia-se no ecossistema florestal, através da coleta do cipó-preto, que, após a colheita, segue para as comunidades, onde ocorre o beneficiamento e a confecção dos artesanatos (cestos). A partir de então, o fluxo pode ter quatro destinos: cooperativa, atacadista, varejista e consumidor. Na cooperativa, a produção pode ser direcionada diretamente para os consumidores ou para a rede atacadista. Os atacadistas, por sua vez, podem vender o produto para os centros de abastecimento, rede de varejo ou diretamente para o consumidor. Já os varejistas vendem o produto para o consumidor final (Figura 1).

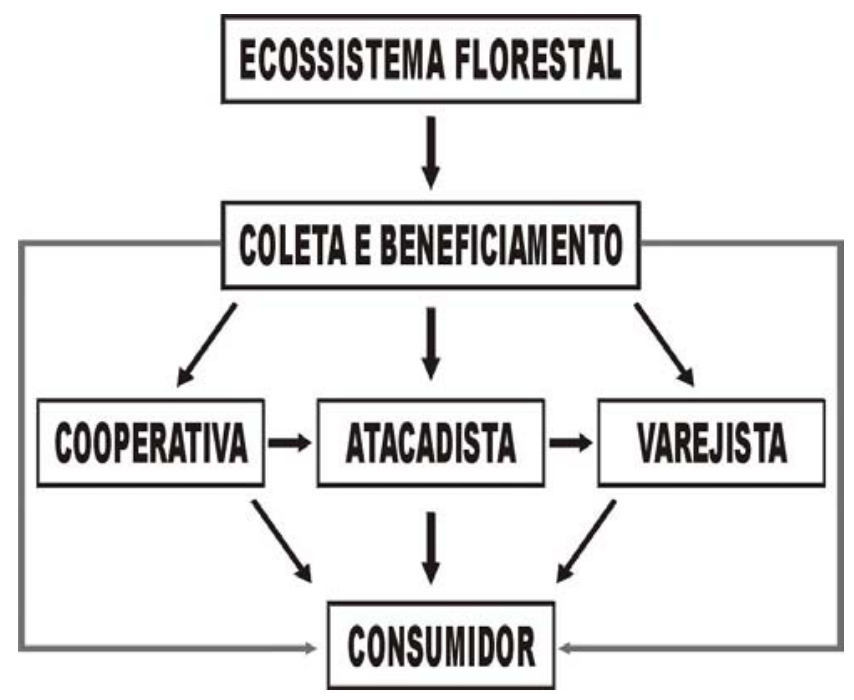

Figura 1. Fluxograma da cadeia produtiva do cipó-preto no litoral paranaense.

Figure 1. Flowchart of the productive chain.

\section{Extração e beneficiamento do cipó-preto}

A atividade de extração do cipó-preto inicia-se nas comunidades, de onde partem equipes formadas principalmente pelos homens da família rumo à floresta, procurando pela espécie. Cada integrante da equipe traz para a comunidade cerca de $40 \mathrm{~kg}$ do cipó bruto por semana. Quantidades 
extraídas superiores a esse limite necessitam de licença especial do órgão físcalizador, nesse caso o Instituto Ambiental do Paraná (IAP). Atualmente, os extratores têm percebido que essa matéria-prima é escassa e que explorá-la de maneira racional é a melhor solução. Para tanto, buscam otimizar a extração através do manejo, como o rodízio de áreas de exploração e poda dos cipós apenas em sua fase adulta. Nessa poda, são tomados os cuidados para garantir a rebrota que, uma vez bem conduzida, proporciona uma maior brotação. Essas práticas têm sido utilizadas na maioria dos casos, pois garantem resultados em curto prazo, como, por exemplo, a redução das distâncias percorridas para a extração e a maior brotação nas árvores, além de preservação da espécie.

Depois de efetuada a coleta, já na comunidade de extratores o cipó é descascado, para se obter o cipó limpo e na tonalidade clara e seca. Essa atividade é desenvolvida em uma espécie de varal e tem um período médio de duração de dez dias. Na confecção artesanal dos cestos, é predominante a mão-de-obra feminina, a qual divide essa atividade com atividades de casa.

\section{Aspectos econômicos}

O preço do artesanato fabricado a partir do cipó-preto varia muito em função do tamanho (peso) e da dificuldade na confecção de certas peças. Em função disso, e com o intuito de facilitar às análises, foi necessário agrupar os produtos em três categorias: cestos pequenos (CP), pesando menos de $100 \mathrm{~g}$; cestos médios (CM), com peso variando entre $100 \mathrm{~g}$ e $200 \mathrm{~g}$; e cestos grandes (CG), pesando mais de $200 \mathrm{~g}$.

\section{Fluxo físico}

A análise do fluxo físico da cadeia produtiva do cipó-preto no litoral paranaense evidenciou a existência de aproximadamente 200 produtores envolvidos com a produção de artesanatos. Esses artesãos coletavam mensalmente aproximadamente $23.000 \mathrm{~kg}$ de cipó-preto e produziam cerca de 77.760 unidades/mês de artesanatos dos mais variáveis tamanhos e modelos. Cerca de $45 \%$ dos produtores pesquisados viviam exclusivamente da produção de artesanato. A média de produção desses produtores chegava a 2.834 unidades/mês do cesto pequeno, 600 unidades/mês do cesto médio e 60 unidades/mês do cesto grande. Para o restante dos produtores (55\%), a produção de artesanatos representava apenas um complemento da renda mensal. Esses produtores produziam em média 350 unidades/mês do cesto pequeno e 50 do cesto médio, não ocorrendo a produção de cestos grandes. Cerca de $20 \%$ da produção total dessa região era destinada para grandes atacadistas localizados em Guaratuba (PR) e Garuva (SC). A maioria da produção - $80 \%$ - era levada por outros atacadistas para os estados de São Paulo e Minas Gerais, constatando a chamada exportação interna, ou seja, para outros estados da federação. Não foi verificado nenhum indício de comercialização desses produtos com outros países.

Os atacadistas que vinham de outros estados trabalhavam em forma de consórcio com os artesãos mais humildes, fornecendo-lhes o fundo de madeira para a confecção dos cestos, já cortado nos tamanhos e formatos desejados. Além disso, garantiam a compra de toda a produção de artesanatos dessa população.

Segundo os comerciantes do litoral paranaense, a média de venda dos cestos confeccionados com cipó-preto chegava a 120 unidades/mês do cesto pequeno, 65 unidades/mês do cesto médio e 36 unidades/mês do cesto grande.

\section{Fluxo Financeiro}

\section{Custo e preço médio dos artesanatos de cipó-preto}

Na produção dos artesanatos pequenos e médios, contabilizam-se os custos de mão-de-obra e matéria-prima (cipó beneficiado), enquanto que na produção do cesto grande também é contabilizada a utilização de outros materiais (verniz, pincel e alça). Para o atacadista, somam-se a margem de lucro do produtor e o custo de transporte. Na tabela 1, são apresentados os custos de produção e preços obtidos para cada um dos produtos nos diferentes elos de comercialização da cadeia produtiva do cipó-preto no litoral paranaense.

\section{Margem Bruta $(\mathrm{Mb})$}

No que se refere à margem bruta de comercialização, evidenciou-se grande amplitude de variação entre os elos de comercialização da cadeia produtiva do cipó-preto (Tabela 2). 
Tabela 1. Média de preços nos diferentes elos que compõem a cadeia produtiva.

Table 1. Average of prices in the different links that the productive chain composes.

\begin{tabular}{lcccc}
\hline \multirow{2}{*}{ Tipo } & $\begin{array}{c}\text { Custo de produção } \\
\text { (R\$/unidade) }\end{array}$ & Produtor & Atacado & Varejo \\
\cline { 3 - 5 } & 0,07 & 0,11 & 0,85 & 1,40 \\
CP & 0,14 & 0,35 & 1,73 & 3,57 \\
CM & 4,50 & 6,17 & 10,50 & 16,00 \\
CG & 1,18 & 2,21 & 4,36 & 6,8 \\
Média & & & & \\
\hline
\end{tabular}

Tabela 2. Percentuais de margem de comercialização de artesanatos de cipó-preto no litoral paranaense maio/2004.

Table 2. Percentages of edge of commercialization of handicraft of black vine - may/2004.

\begin{tabular}{lcccc}
\hline \multirow{2}{*}{ Tipo } & \multicolumn{4}{c}{ Margem (\%) } \\
\cline { 2 - 5 } & Produtor & Atacado & Varejo & Total \\
\hline CP & 2,86 & 52,85 & 39,28 & 92,14 \\
CM & 5,88 & 38,65 & 51,54 & 90,19 \\
CG & 10,44 & 27,06 & 34,37 & 61,43 \\
Média & 6,39 & 39,52 & 41,73 & 81,25 \\
\hline
\end{tabular}

Observou-se que $41,79 \%$ dessa margem de comercialização são apropriados pelo varejista, enquanto o atacadista apropria-se em média de $39,52 \%$, restando $6,4 \%$ para o produtor. A margem total média de comercialização é de $81,45 \%$, e refere-se à diferença entre o preço pago pelo consumidor e o preço pago ao produtor.

Markup de comercialização

Quanto ao Markup de Comercialização ${ }^{1}$ no interior da cadeia produtiva do cipó-preto (Tabela 3), observou-se que o atacadista representava o principal responsável pela alteração de preço, aumentando em média 388,09\% o preço pago ao produtor, enquanto que o varejista acrescentava um markup médio de $74,28 \%$. Entretanto, a maioria dos custos da cadeia produtiva ficava a cargo do atacadista. Esses custos correspondiam ao transporte e despesas tributárias e fiscais, o que explica o markup de 388,09\%. O varejista não conta com tais despesas, repassando o produto acabado ao consumidor final. Assim, este paga em média $770,09 \%$ a mais sobre o preço pago ao produtor.

Tabela 3. Markup de comercialização dos artesanatos de cipó-preto - jun/2004.

Table 3. Commercialization markup of black vine handicraft.

\begin{tabular}{lcccc}
\hline \multirow{2}{*}{ Tipo } & \multicolumn{3}{c}{ Markup (\%) } \\
\cline { 2 - 5 } & Produtor & Atacado & Varejo & Total \\
\hline CP & 36,36 & 672,73 & 64,70 & 1172,72 \\
CM & 60,00 & 395,24 & 105,76 & 919,05 \\
CG & 37,04 & 96,30 & 52,38 & 218,51 \\
Média & 44,47 & 388,09 & 74,28 & 770,09 \\
\hline
\end{tabular}

\section{CONSIDERAÇÕES FINAIS}

Apesar de sua simplicidade, um dos maiores problemas da cadeia produtiva do cipó-preto é a falta de organização dos produtores, tanto do ponto de vista econômico quanto produtivo.

\footnotetext{
${ }^{1}$ Markup de Comercialização, em termos absolutos, corresponde à margem de comercialização, porém, em termos relativos, retrata o percentual de aumento entre os preços de venda e de compra relativamente ao preço de compra.
} 
O baixo preço unitário pago pelos artesanatos e a falta de incentivos econômicos nessa área como, por exemplo, linha de crédito voltada para os pequenos produtores - muitas vezes desestimulam ou inviabilizam essa atividade produtiva. A falta de organização da extração e beneficiamento também afeta a melhoria de renda dos envolvidos.

A legislação é outro fator que deve ser revisto, pois o fato de a coleta em grande escala do cipópreto ser ilegal em seu hábitat natural não tem impedido que muitos produtores realizem essa prática, o que pode acarretar no futuro uma falta desse recurso. A fiscalização não ocorre periodicamente e não impede a degradação, apenas ameniza. Finalmente, há que se desenvolver uma política de apoio às comunidades extrativistas da APA de Guaratuba, apoio este que envolve campanhas de conscientização, assistência técnica e inclusão de conhecimentos, aliado à concessão de incentivos econômicos, revisão da legislação específica e pesquisas de caráter econômico, resolvendo a instabilidade dessas atividades, uma vez que as margens e markups de comercialização evidenciam que a maior parte do lucro fica com os atacadistas, sendo estes responsáveis por mais da metade do total de acréscimo do preço sofrido pelo produto após sua saída da propriedade.

\section{REFERÊNCIAS}

IBAMA. Dísponível em: <http://www.ibama.gov.br> Acesso em: 23 out. 2003.

KOTLER, P. Administração de marketing: a edição do novo milênio. 10.ed. São Paulo: Prentice Hall, 2000. 764p.

NEPSTAND, D. C. Non-timber products from the tropical forests - evaluation of a conservation and development strategy. Advances in economic botany, New York, v.9, p.7-9, 1992.

REYDON, B. P.; SCHLOGL, A. K. S. B.; HENRY, G. Produtos florestais não madeireiros da Amazônia: limites e perspectivas enquanto alternativa para o desenvolvimento sustentável da região. Floresta, Curitiba, n.esp., p.127-133, set., 2002.

SANTOS, A. J. dos; CORSO, N. M.; MARTINS, G.; BITTENCOURT, E. Aspectos produtivos e comerciais do pinhão no estado do Paraná. Floresta, Curitiba, v.32, n.2, p.163-169, jul./dez., 2002.

SONDA, C. Comunidades rurais tradicionais da área de proteção ambiental estadual de Guaratuba: caracterização sócio-econômica e utilização dos recursos vegetais silvestres. 193f. Tese (Doutorado em Ciências Florestais) - Setor de Ciências Agrárias, Universidade Federal do Paraná, Curitiba, 2002. 